\title{
PENINGKATAN HASIL BELAJAR BAHASA ARAB DI ERA PENDEMI MELALUI METODE VIDEO BASE LEARNING SISWA KELAS X IPS SMAIT BAITUSSALAM PRAMBANAN
}

\author{
Shira Bella \\ UIN Sunan Kalijaga Yogyakarta \\ shirabella@gontor.ac.id
}

\author{
Bayu Andri Pratama \\ UIN Sunan Kalijaga Yogyakarta \\ bayuandri444@gmail.com
}

\author{
Rasuludin \\ UIN Sunan Kalijaga Yogyakarta \\ uddin.rasul@gmail.com
}

\begin{abstract}
This research is a classroom action research that aims to find out the improvement of the results of learning Arabic through the video base learning method of grade X IPS SMAIT Baitussalam prambanan. The subject of this study was grade $X$ students of SMAIT Baitussalam school year 2020/2021 a total of 20 students. Research is carried out with 2 cycles namely cycle I and cycle II. The research stage conducted in cycles I and II includes 4 stages, namely: planning stage, implementation stage, observation and reflection stage. In the implementation stage the researcher is slightly different because the learning is not done in the classroom but the students and teachers are in different places. Based on the results of the study in cycle I obtained the average grade value is 60.25 included in less predicate. While the result in cycle II is obtained the average grade value is 90.25 included in the high predicate. Thus, from the results of cycle I research and cycle II student learning results increased by $30 \%$.
\end{abstract}

Keywords : Learning Results; Arabi; Video Base Learning.

\begin{abstract}
Abstrak: Penelitian ini merupakan penelitian tindakan kelas yang bertujuan untuk mengetahui peningkatan hasil belajar bahasa arab melalui metode video base learning siswa kelas X IPS SMAIT Baitussalam Prambanan. Subjek penelitian ini adalah siswa kelas X IPS SMAIT Baitussalam tahun ajaran 2020/2021 sejumlah 20 siswa. Penelitian dilaksanakan dengan 2 siklus yaitu siklus I dan siklus II. Tahapan penelitian yang dilakukan pada siklus I dan II mencakup 4 tahap yaitu : tahap perencanaan, tahap pelakasanaan, tahap pengamatan/observasi dan refleksi. Dalam tahap pelaksanaannya penelitian sedikit berbeda karena pembelajaran tidak dilakukan di dalam kelas melainkan siswa dan guru berada di tempat yang berbeda. Berdasarkan hasil penelitian pada siklus I didapatkan nilai rata-rata kelas adalah 60,25 termasuk dalam predikat kurang. Sedangkan hasil pada siklus II didapatkan nilai rata-rata kelas adalah 90,25 termasuk dalam predikat tinggi. Maka, dari hasil penelitian siklus I dan siklus II hasil belajar siswa mengalami peningkatan $30 \%$.
\end{abstract}

Kata Kunci: Hasil Belajar; Bahasa Arab; Video Base Learning. 


\section{PENDAHULUAN}

Media Pembelajaran merupakan perangkat yang berperan penting dalam sebuah pembelajaran. Identifikasi suatu pembelajaran yang baik adalah yang mampu memperoleh hasil belajar siswa yang maksimal. Hasil belajar menurut Sutratinah (2001:3) adalah suatu penilaian hasil dari kegiatan belajar yang dinyatakan dalam bentuk simbol, angka, huruf atau kalimat yang mencerminkan hasil yang sudah dicapai oleh siswa dalam jangka waktu tertentu. Hasil belajar seorang siswa dipengaruhi oleh berbagai faktor, didalamnya terdapat motivasi belajar, metode pembelajaran, sarana dan prasarana salah satunya berupa media pembelajaran.

Sarana belajar seperti buku memang sangat dibutuhkan dalam sebuah pembelajaran untuk memahami materi pelajaran, akan tetapi dalam pelaksanaannya tidak semua siswa memiliki buku pada saat proses pembelajaran, sedangkan siswa yang memiliki buku belum tentu mengerti dan memahami materi yang ada di dalam buku tersebut, selain itu penggunaan metode ceramah yang kurang menarik juga mempengaruhi hasil siswa. Untuk menunjang hasil belajar siswa dalam proses pembelajaran, guru memerlukan sarana yang tepat dalam menyampaikan materi dengan baik maupun menarik sehingga dapat dimengerti dan dipahami oleh siswanya.

Di era revolusi 4.0, teknologi dalam suatu proses belajar mengajar bisa menjadi media pembelajaran, dan sumber belajar bagi siswa. Sebagai sumber belajar, teknologi merupakan alat untuk memperlancar pembelajaran yang lebih menarik bagi siswa, sehingga dimungkinkan pula dapat memperoleh hasil belajar yang sesuai dengan harapannya. Diantara banyak teknologi pembelajaran salah satunya adalah dengan media video, yang memiliki kelebihan untuk pelaksanaan pembelajaran.

Berdasarkan data observasi bersama beberapa guru pengajar bahasa arab hasil belajar siswa sebagian besar belum mencapai KKM, serta didapatkan nilai rata-rata hasil PTS kelas X IPS adalah 55,60 atau terdapat 35\% (7 siswa) yang tuntas dan 65\% (13 siswa) yang tidak tuntas. Hal ini dipengaruhi berbagai faktor yaitu faktor internal yang berasal dari dalam diri siswa seperti beberapa dari siswa tidak mengikuti pembelajaran dengan maksimal dan faktor eksternal seperti strategi pembelajaran, media pembelajaran, metode pembelajaran, dll yang kurang tepat. Pada bulan Maret 2020 di Indonesia mulai ada isu penyebaran Covid-19, yang mengharuskan para siswa belajar dari rumah. Jika belajar dari rumah, para siswa diawasi oleh orang tua dengan dipandu oleh guru pengajar secara daring. Dengan demikian, dalam proses belajar mengajar mata pelajaran bahasa arab dibutuhkan media pembelajaran yang menarik agar siswa dapat mengerti dan memahami materi dengan baik. Sedangkan dalam pembelajaran bahasa arab tidak hanya mempelajari teori, akan tetapi praktek membaca, menulis dan berbicara dalam bahasa arab, dan juga dibutuhkan faktor pendukung dalam pembelajaran bahasa arab yaitu, adanya lingkungan bahasa arab sebagaimana mestinya seperti tatap muka.

Hal diatas menjadi tantangan bagi guru mata pelajaran bahasa arab untuk tetap mampu menciptakan pembelajaran yang baik tanpa mengurangi aspek-aspek penting dalam belajar bahasa arab. Bahasa arab merupakan salah satu bahasa yang digunakan di dunia internasional, dan memiliki nilai sastra tinggi bagi yang memahami dan mendalaminya. Meski pembelajaran dilaksanakan melalui PJJ (Pembelajaran Jarak Jauh), guru harus mampu 
menciptakan lingkungan belajar bahasa arab bagi siswa. Dalam menciptakan lingkungan tersebut guru harus mampu menciptakan rasa keingintahuan untuk menemukan hal baru, rasa ingin beraktifitas (praktik berbahasa), rasa ingin mengajak orang lain agar giat berbahasa arab, rasa ingin mengetahui dan memecahkan masalah dalam persoalan (aktif menjawab pertanyaan), rasa untuk aktualisasi diri dan adaptasi terhadap lingkungan berbahasa (Brown, 1994:143). Maka, di masa pandemi ini salah satu metode yang dapat diterapkan untuk dapat menciptakan lingkungan tersebut adalah dengan metode Video Base Learning.

Video Base Learning adalah metode pembelajaran yang menggunakan video dan audio dengan cara direkam, sehingga berfungsi untuk membantu dalam proses pembelajaran. Pembelajaran berbasis video ini meliputi: animasi, live action yang bisa menjadi contoh, video tutorial, documenter, vlog, dll. Dengan metode ini guru dapat memberikan stimulus pada tiga bagian dalam pembelajaran yaitu: emosional, intelektual dan psikomotorik. Dan metode pembelajaran ini menurut peneliti sangat cocok digunakan untuk generasi diera resolusi 4.0 dan dimasa pendemi ini, karena memiliki beberapa alasan yaitu: dapat menciptakan lingkungan belajar yang menyenangkan dan membuat semakin motivasi siswa untuk belajar, membuat siswa lebih mudah untuk mempelajari dan memahami sebuah materi belajar, membuat siswa dapat belajar secara mandiri untuk praktik membaca, menulis ataupun berbicara dalam bahasa arab sesuai dengan materi yang dipelajari melalui video tutorial di yotube dan dapat diakses dengan internet, dan yang paling penting meski hanya satu atau dua kali melakukan pembuatan video pembelajaran, namun dapat disaksikan dari generasi ke generasi tanpa menghilangkan konsistensi meteri, isi, efek, tujuan, dll. Metode ini merupakan salah satu metode yang menggunakan media audio-visual, dimana media ini gabungan dari beberapa panca indra manusia, tidak hanya mendengarkan penjelasan guru akantetapi siswa dapat melihat langsung mimik dalam pengucapan, tulisan arab, dll yang ditampilkan oleh guru dalam media pembelajaran. Menurut Baugh dalam Arsyad (1997:10) menyatakan bahwa untuk memperoleh hasil belajar seseorang kurang lebih $90 \%$ melalui panca indra pengelihatan, 5\% melalui panca indra pendengaran dan 5\% lagi dari panca indra lainnya.

Dalam penelitian skripsi Awalia tahun 2015 tentang peningkatan prestasi belajar bahasa arab melalui media permainan, didapatkan data sebelum dilakukan menggunakan media permainan presentase $31,57 \%$ yang tuntas dan $68,43 \%$ yang belum tuntas memenuhi KKM. Dan setelah dilakukan siklus 1 didapat data 42,10\% siswa yang tuntas dan 57,90\% siswa yang belum tuntas KKM, meski ada penigkatan namun masih dibawah KKM, setelah dilakukan refleksi pada siklus I terjadi peningkatan pada siklus II yaitu 94,73\% yang tuntas dan $5,27 \%$ yang belum tuntas KKM.

\section{METODE PENELITIAN}

Metode penelitian yang digunakan oleh peneliti adalah penelitian tindakan kelas (PTK) untuk meningkatkan hasil belajar bahasa arab di era pandemic melalui metode video base learning. Penelitian ini dilakukan pada pada mata pelajaran Bahasa Arab dengan materi Al'Adad lil mudzakar wa muanats. Subjek penelitian ini adalah siswa kelas X IPS SMAIT Baitussalam tahun ajaran 2020/2021 sejumlah 20 siswa. 
Penelitian ini merupakan penelitian tindakan kelas. Penelitian ini dilakukan sebagai strategi pemecahan masalah untuk meningkatkan hasil belajar siswa dengan memanfaatkan metode video base learning dengan menggunakan kinemaster dan youtube sebagai medianya kemudian melakukan refleksi terhadap hasil tindakan. PTK merupakan upaya yang bertujuan untuk memperbaiki proses pembelajaran atau memecahkan masalah yang dihadapi dalam pembelajaran bahasa arab guna meningkatkan hasil belajar siswa kelas X IPS SMAIT Baitussalam. Penelitian dilakukan setelah PTS (Penilaian Tengah Semester) pada hari Sabtu, 26 September 2020.

Instrumen pengumpulan data adalah observasi pelakasanaan proses pembelajaran daring melalui video pembelajaran dan tes. Sedangkan analisis datanya menggunakan teknik analisis deskriptif kualitatif dan kuantitatif menggunakan KKM (Kriteria Ketuntasan Minimal) matapelajaran bahasa arab yaitu 65. Berdasarkan hasil observasi pada siklus II didapatkan 5\% (1 siswa) yang belum tuntas KKM dan 95\%(19 siswa) yang tuntas KKM dengan nilai rata-rata kelas adalah 90,25. Hasil pada siklus II termasuk dalam predikat tinggi.

\section{HASIL DAN PEMBAHASAN}

Penelitian dilaksanakan dengan 2 siklus yaitu siklus I dan siklus II. Tahapan penelitian yang dilakukan pada siklus I mencakup 4 tahap yaitu : (1) tahap perencanaan dengan mempersiapkan materi dan perangkat pembelajaran yang terdiri dari RPP yang dilakukan dengan prinsip efisiensi, keefektifan dan berorientasi kepada siswa sebagaimana tercantum pada surat edaran MENDIKBUD RI No. 14 Tahun 2019 tentang Penyederhanaan RPP, mempersiapkan media pembelajaran, lembar kerja, lembar observasi (2) tahap pelakasanaan dengan memberikan materi melalui whatsapp grup, mengintruksikan dan membimbing untuk mengunduh alat bantu dengan aplikasi durus al-lughoh gontory (Imam Zarkasyi dan Imam Syubani), memberikan video pembelajaran yang dibuat oleh pengajar melalui aplikasi youtube serta membimbingnya. (3) tahap pengamatan/observasi dilihat dari hasil belajar siswa dan hasil observasi, (4) refleksi. Keempat tahap yang dilakukan peneliti sedikit berbeda karena pembelajaran tidak dilakukan di dalam kelas melainkan siswa dan guru berada di tempat yang berbeda.

Berdasarkan hasil tes evaluasi pada siklus I didapatkan 50\% (10 siswa) yang belum tuntas KKM dan 50\% (10 siswa) yang tuntas KKM dengan nilai rata-rata kelas adalah 60,25. Rentang predikat yang di tetapkan sekolah SMAIT Baitussalam untuk mata pelajaran bahasa arab dengan berdasarkan KKM adalah sebagai berikut:

Tabel 1. Rentang Predikat Berdasarkan KKM

$$
\text { Rentang Predikat }=\frac{\text { nilai maksimum }-\mathrm{KKM}}{3}=\frac{100-65}{3}=
$$




\begin{tabular}{|c|c|c|}
\hline NO & RENTANG NILAI & PREDIKAT \\
\hline 1 & $89-100$ & Sangat Baik \\
\hline 2 & $77-88$ & Baik \\
\hline 3 & $65-76$ & Cukup \\
\hline 4 & $<65$ & Kurang \\
\hline
\end{tabular}

Jadi hasil tes pada siklus I menurut predikat diatas termasuk dalam predikat kurang. Meski terdapat peningkatan apabila dibandingkan dengan nilai PTS, akan tetapi hanya terdapat 50\% (10 siswa) yang tuntas KKM. Setelah mengetahui hasilnya, maka perlu diadakan refleksi untuk memperbaiki kekurangan dan kendala pada siklus I lalu mencari solusi yang nantinya akan diterapkan pada siklus II dengan harapan terjadi peningkatan yang signifikan.

Dalam hasil observasi siswa aspek yang diperhatikan meliputi: (1) aspek motivasi dilihat dari kesemangatnnya dan ketepatan waktu dalam mengikuti pembelajaran bahasa arab,(2) aspek keaktifan dilihat dari keaktifan siswa dalam bertanya dan menjawab pertanyaan, (3) aspek perhatian dilihat dari sikap siswa saat mengikuti proses pembelajaran (banyak siswa yang menonton video pembelajaran yang di uploud pada aplikasi youtube). Dan hasil observasi pada siklus I dapat disimpulkan bahwa motivasi saiswa dalam belajar bahasa arab hanya 5 siswa, pada aspek keaktifan menjawab dan keberanian bertanya hanya 6 siswa, sedangkan aspek perhatian ada 15 siswa yang menonton video pembelajran yang diberikan.

Pada pelaksanaan siklus II guru melakukan langkah-langkah yang sama dengan langkah-langkah pada siklus I, namun ada perbaikan dalam pelaksanaannya yang sesuai dengan hasil refleksi pada siklus I, yaitu selain pemberian video materi yang berisi kosakata dan teori, guru juga memberikan video percakapan langsung dalam kehidupan sehari-hari serta penjelasan virtual melalui google meet guna mempermudah dalam pemahaman siswa. Berdasarkan hasil tes evaluasi pada siklus II didapatkan 5\% (1 siswa) yang belum tuntas KKM dan 95\%(19 siswa) yang tuntas KKM dengan nilai rata-rata kelas adalah 90,25. Hasil pada siklus II termasuk dalam predikat tinggi.

Dalam hasil observasi siswa pada siklus II aspek yang diperhatikan sama dengan aspek yang dinilai pada siklus I. Dan hasil observasi pada siklus II dapat disimpulkan bahwa motivasi saiswa dalam belajar bahasa arab meningkat menjadi 10 siswa, pada aspek keaktifan menjawab dan keberanian bertanya juga meningkat menjadi 15 siswa, sedangkan aspek perhatian meningkat menjadi 19 siswa yang menonton video pembelajaran yang diberikan.

Maka, dari hasil tes evaluasi siklus I dan siklus II hasil belajar siswa mengalami peningkatan $30 \%$. Berikut tabel rekapitulasi hasil belajar siswa kelas X IPS pada siklus I dan siklus II. 
Tabel 2. Rekapitulasi Hasil Belajar Siswa Berdasarkan Predikat KKM

\begin{tabular}{|c|c|c|l|}
\hline NO & SIKLUS & RATA-RATA & PREDIKAT \\
\hline 1 & I & 60.25 & KURANG \\
\hline 2 & II & 90.25 & TINGGI \\
\hline \multicolumn{2}{|c|}{ PENINGKATAN } & \multicolumn{2}{|c|}{} \\
\hline
\end{tabular}

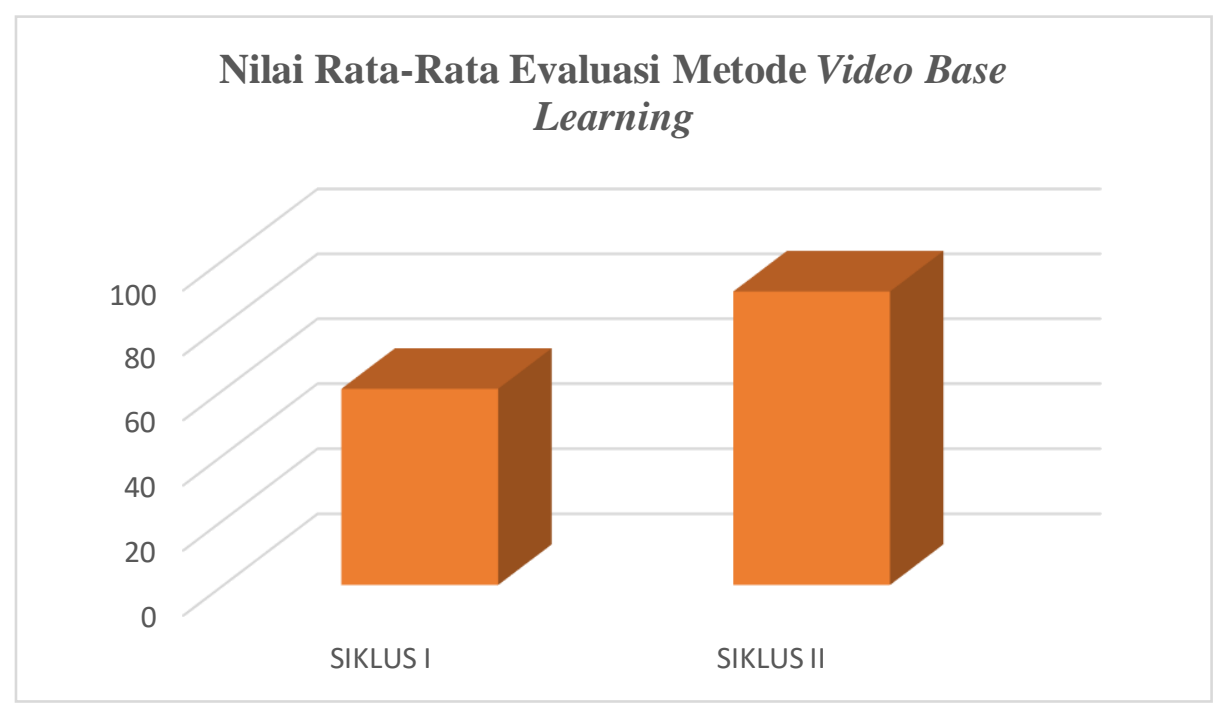

\section{Gambar 1. Grafik perbandingan nilai rata-rata siklus I dan siklus II}

Metode video base learning dapat meningkatkan hasil belajar siswa pada matapelajaran bahasa arab di era pandemi Covid-19, karena dalam pelaksanaannya metode ini memberikan kontribusi yang sangat signifikan dalam peningkatan hasil belajar siswa pada mata pelajaran bahasa arab dan membuat pembelajaran daring lebih menarik dan mudah difahami meski tidak tatap muka secara langsung. Walaupun belum semua siswa kelas X IPS tuntas sesuai dengan KKM karena terdapat beberapa faktor yang mempengaruhinya, maka perlu kerja sama dari seluruh warga sekolah maupun orang tua.

\section{KESIMPULAN}

Berdasarkan hasil dan pembahasan pada penelitian tindakan kelas ini, maka peneliti menyimpulkan bahwa terdapat peningkatan yang signifikan setelah diadakan penelitian menggunakan metode video base learning, hal ini terbukti dari hasil tes pada siklus I dan siklus II selalu terjadi peningkatan. Nilai rata-rata hasil PTS kelas X IPS adalah 55,60 atau terdapat 35\% (7 siswa) yang tuntas dan 65\% (13 siswa) yang tidak tuntas. Setelah dilakukan penelitian pada siklus I nilai rata-rata tes evaluasi adalah 60,25 atau 50\% (10 siswa) yang belum tuntas KKM dan 50\% (10 siswa) yang tuntas KKM. Sedangkan pada siklus II nilai rata-rata tes evaluasi adalah 90,25 atau 5\% (1 siswa) yang belum tuntas KKM dan 95\%(19 siswa) yang tuntas KKM.

Kelebihan dari metode ini adalah dapat disaksikan dari generasi ke generasi tanpa menghilangkan konsistensi meteri, isi, efek, tujuan, dll. Dapat menggantikan guru untuk tetap 
bisa memberikan aspek-aspek penting dalam belajar bahasa arab tanpa harus tatap muka. Dengan metode ini pembelajaran lebih menarik, tidak membosankan dan mudah difahami oleh siswa dengan tambahan animasi, trik, tutorial, dll. Terdapat efesiensi waktu yang baik dalam penjelasan materi yang dirasa sulit utuk dijelaskan.

Kekurangan dari metode ini adalah guru harus memiliki keahlian khusus untuk membuat dan mengedit sebuah video pembelajaran agar terlihat menarik. Metode ini dibutuhkan kuota internet/wifi untuk mengirim dan mengakses video. Pada metode ini guru tidak dapat mengetahui pemahaman siswa secara langsung karena guru dan siswa berada di tempat yang berbeda, maka dibutuhkan pertemuan secara virtual maupun tes evaluasi agar dapat mengetahui tingkat pemahaman siswa dari video yang diberikan.

\section{DAFTAR PUSTAKA}

Arsyad, Azhar. (1997). Media Pembelajaran. Jakarta: Raja Grafindo Persada.

Brown H. Douglas. (1994). Usus Ta'allum al-Lughah wa Ta'limuha, diterjemahkan oleh ‘ Abduh al-Tajihi dan Ali Ahmad Sya'ban. Beirut: Dar al-Nahdhah al 'Arabiyyah.

Cahyo, Edo Dwi. (2017). Peningkatan Aktivitas Dan Hasil Belajar Siswa Menggunakan Media Realia Pada Pembelaaran IPS. Jurnal Pendidikan Progresif: V. 1. N. 7 P.32-38.

Nurhayati, Erlis. (2020). Meningkatkan Keaktifan Siswa Dalam Pembelajaran Daring Melalui Media Game Edukasi Quiziz pada Masa Pencegahan Penyebaran Covid-19. Jurnal Penelitian dan Pengembangan Pendidikan: V. 3. n. 7. P.145-150.

Kemendikbud. (2016). Permendikbud No. 23 Tahun 2016 tentang Standar Penilaian Pendidikan Dasar dan Menengah.

Mamin, R,. \& Rifda, N. H. A. (2019). Efektivitas Media Pembelajran Video Tutorial Terhadap Hasil Belajar Mahasiswa Pada Matakuliah IPA Sekolah, Prosiding Seminar Nasional Lembaga Penelitian Universitas Negri Makasar.

Tirtonegoro, S. (2001). Anak Supernormal dan Program Pendidikannya. Jakarta: Bina Aksara. 